\title{
LOS ÓRGANOS HISTÓRICOS DE LA CATEDRAL DE MÉXICO
}

\author{
Gustavo Delgado PARRA
}

\begin{abstract}
This article contains a summary description of historical organs from the Mexican Cathedral. It begins with a historical synthesis of the instruments and goes on to analyze their acoustical design and concludes with a brief reference to their current state. Without doubt, these instrument are the most important of their kind in the whole of the American Continent. It is common knowledge that they were restored thirty years ago by the Dutch company in Zaandam called Flentrop Orgelbouw. Now, three decades later, they are to be newly restored and we truly hope that successfully so, and that such extremely important instruments will thus consolidate their heritage.
\end{abstract}

\section{Resumen}

El presente artículo es una descripción sumaria de los órganos históricos de la catedral de México. Inicio con una síntesis histórica de los instrumentos, posteriormente hago un análisis de su composición fónica, y concluyo con una breve reseña de su estado actual. Sin lugar a dudas, estos instrumentos son los más importantes en su tipo en el continente americano. Como es bien sabido, estos fueron restaurados hace treinta años por la compañía Flentrop Orgelbouw de Zaandam, Holanda. Actualmente, a tres décadas, se proyecta una nueva restauración. Hacemos votos para que este proyecto se consolide en beneficio de la recuperación patrimonial de tan importantes instrumentos.

La Catedral de México alberga en su interior dos magníficos órganos:

El órgano de la Epístola fue construido en España en 1693 por Jorge de Sesma1, para la catedral de México. La comisión para la construcción del órgano la recibió el año de 1688, sin embargo no le tocaría ver su obra concluida ya que muere en Madrid en 1690. Las fachadas del órgano y la sillería del coro fueron construidas y diseñadas por el arquitecto y maestro de carpintería Juan de Rojas. El instrumento fue puesto en servicio el 15 de abril de 1695, después de 2 años de trabajos in situ.

1. Jorge de Sesma, miembro de una distinguida familia de organeros aragoneses, fue hijo de José de Sesma Infanzón, autor de importantes instrumentos construidos para las iglesias de Nuestra Señora del Pilar, San Pablo y la Seo en Zaragoza, entre otros. El nombre de Jorge de Sesma aparece al lado del de su padre, José, en el contrato para la construcción del órgano de Teruel, España, en 1685. Poco tiempo después, Jorge de Sesma se instala en Madrid, en donde recibiría la comisión para la construcción del órgano para la catedral de México. 
El órgano del Evangelio fue construido por completo en la Nueva España (México) por José Nasarre $^{2}$ en 1735. Nassarre hizo una serie de modificaciones al órgano de la Epístola (Sesma), entre otras, la adición de una cadereta de espaldas, habiendo logrado una simetría entre ambos instrumentos. La reconstrucción y ampliación del órgano de la Epístola, a manos de Nassarre, fue completada un año después de haber concluido el órgano del Evangelio, en 1736.

\section{Breve perfil histórico}

El valor patrimonial de los órganos históricos en México es incalculable, estos instrumentos son testigos vivos de nuestra historia, como fruto inmediato del "encuentro de dos mundos". A sólo una década de la caída de Tenochtitlan y la fundación de la ciudad de México, un órgano para la primera catedral fue importado de Sevilla en 1530, con el propósito de acompañar una pequeña capilla de música que Fray Pedro de Gante tenía bajo tutela en una escuela de Texcoco ${ }^{3}$.

Ya en 1554 la mayoría de las grandes catedrales no solamente tenían órganos, sino también coplas de ministriles; tal es el caso de la catedral de México. La música se hacía en ese tiempo, tanto por españoles como por indígenas, quienes fueron instruidos por los misioneros. Este fenómeno adquirió rápidamente proporciones tales que llegaron a causar gran polémica entre las autoridades eclesiásticas. Los excesos llamaron incluso la atención del rey Felipe II de España, quien en 1551 ordenó una reducción en el número de puestos para músicos que ocupaban los indígenas ${ }^{4}$.

La demanda de órganos se acrecentó a finales del siglo XVI en medio del esfuerzo del clero por limitar el empleo de músicos indígenas, particularmente instrumentistas. Esto coincidió con la amplia reforma llevada a cabo en la música religiosa española como consecuencia de las resoluciones del Concilio de Trento (1543-1563) que culminaron con la decisión de Felipe II, de expulsar todos los instrumentos, con excepción del órgano, de su propia capilla 5 .

En la ciudad de México existían ya dos órganos en la primera catedral alrededor de 1613, y un "artífice de órganos": Francisco Hernández de Porres, quien tenía a su cargo el mantenimiento y afi-

2. Por el momento no contamos con información relativa a Nassarre y su obra anterior a 1730 . Sabemos que a poco tiempo de haber llegado a México, procedente de España, construyó el órgano de la catedral de Guadalajara, Jalisco, en 1730. El instrumento es descrito por la Gazeta de México en el número de diciembre de ese mismo año. En 1732 completa el gran órgano de la catedral de Valladolid, hoy Morelia, Michoacán. Concluidos los trabajos en Morelia, se traslada a la ciudad de México en donde recibe la comisión para hacer algunos arreglos y modificaciones al órgano de Sesma de la catedral metropolitana. Durante su permanencia en la ciudad de México realizó otros proyectos importantes, como aquel del órgano de la Basílica de Guadalupe. Cabe preguntarse, ¿acaso José Nassarre tuvo algún nexo familiar con el ilustre aragonés Fray Pablo Nassarre, organista del Monasterio de San Francisco de Zaragoza, compositor y tratadista, autor de la Escuela Música... Zaragoza 1723, 1724; así como de los Fragmentos Músicos, Madrid 1700 ?. Esta es una conjetura aún por resolver.

3. -Robert M. Stevenson: Music in México. New York, Thomas Y. Crowell Company, 1952, p. 84.

4. -Genaro GARCía: El Clero de México durante la dominación española. México, Doc. inéd. ó muy raros, 1907, volumen $\mathrm{XV}, \mathrm{pp} .141-142$

5. Pese a esas intenciones hay que señalar que los conjuntos de ministriles no llegaron a desaparecer ni en México ni en España; en la misma Capilla Real hay testimonio de uso de ministriles e instrumentistas de cuerda a finales del siglo XVI y principios del XVII: $c f r$ L. ROBLEDO, "Vihuelas de arco y violones en la corte de Felipe III", en Actas del Congreso Internacional "España en la Música de Occidente" (Salamanca, 1985), Madrid, INAEM, 1987, vol. II, pp.63-76. Vid.: -Jaime Moll RoQUETA: "Los villancicos cantados en la Capilla Real a fines del siglo XVI y principios del XVII”, en Anuario Musical, XXV (1970), pp.81-96. 
nación de los instrumentos, de manera permanente. Estos órganos deben haber sido transferidos a la nueva catedral metropolitana una vez que el coro fue terminado.

La República mexicana posee un gran patrimonio de órganos históricos de la época "colonial", construidos en particular durante los siglos XVII y XVIII, aunque existen también órganos del siglo XIX e inclusive de principios del XX, manufacturados de acuerdo con el arte organero de la época de la dominación española.

De manera muy general, y a través de la clasificación, tal vez un tanto arbitraria pero hoy comúnmente extendida, de Louis Jambou, se puede decir que hubo dos tendencias principales en la organería española que influyeron fuertemente en la mexicana durante los siglos XVII y XVIII, una procedente de la región de influencia de Castilla (Madrid y el norte de España), a la cual llamaremos aquí "órgano español mayoritario" por su mayor presencia en toda la Península Ibérica, y la otra de Cataluña, Baleares y Levante a la que denominaremos "órgano catalano-levantino" . Habiendo hecho esta aclaración, podemos decir que el estilo "español mayoritario", dominante hacia principios del siglo XVIII, fue claramente la tradición adoptada en México en el sentido antes apuntado, obviamente los modelos que pasan a América lo hacen a través del "tamiz" castellano: los modelos originados en el País Vasco, Navarra y Aragón, se asentaron luego en Castilla, difundiéndose así por el territorio de la corona castellana, que los hizo propios, y pasando de este modo, más tarde, a América a través de las "metrópolis" castellanas: fundamentalmente, Toledo, y —en este último caso, andaluza-, Sevilla. Los organeros de Castilla se interesaron en registros brillantes de lengüetería y otros sonidos exóticos, por ejemplo cornetas, así como en registros partidos (medio registro), mientras que los constructores catalanes tuvieron una tendencia más conservadora. Inspirados por la costumbre flamenca de construir y desarrollar registros de flautas labiales de escala ancha y estrecha, con un menor énfasis en registros penetrantes de lengüetas o de registros partidos en los que se enfatizaba la búsqueda del color. Los registros partidos aparecieron más lentamente en instrumentos "catalano-levantinos", tomando en cuenta que esta visión no deja de ser demasiado simplificadora. Hemos de ser cuidadosos con las clasificaciones regionales o nacionales cuando se habla de los siglos XVI-XVIII, pues la realidad política y cultural de entonces no contemplaba los mismos límites o fronteras que la actual.

En México, tanto los instrumentos como los documentos que sobreviven hasta hoy día, nos indican que los órganos de tamaño y recursos significativos no aparecieron, incluso en las mayores catedrales, sino hasta después de 1650. Algunos investigadores y organólogos creen que esto es el reflejo de una inequívoca influencia "castellana", la cual supuestamente continuó casi sin modificaciones a través de toda la época "colonial" e incluso hasta fines del siglo XIX. Sin embargo, en estudios más recientes, hemos corroborado que la influencia "catalano-levantina", e incluso la italiana, tienen una influencia decisiva en México. Por ejemplo, en la región del actual estado de Oaxaca, en donde la gran mayoría de los órganos aún conservados se circunscribe en el marco de una tradición

6. Esta clasificación, acuñada por L. Jambou, y adoptada por varios estudiosos y organólogos, requiere alguna matización en sus denominaciones. Es cierto que los instrumentos catalanes y mallorquines -y en ciertos casos los valencianos- poseen características diferentes de los del resto de la península; lo que no es necesariamente correcto es llamar estilo "castellano" al modelo de órgano ibérico predominante en toda la península, modelo que procede, claramente, de la zona vasco-navarro-aragonesa. 
ascética -considerando el término desde un punto de vista meramente fónico-tonal-, vinculada a una tradición ortodoxa derivada del Blockwerke medieval. Esta divergencia de estilos, entre el estilo "castellano" y el "catalán", también nos muestra la diferencia existente entre el carácter sacro y secular de un instrumento. Esta diferencia de conceptos entre el carácter sacro y el secular tamizó al órgano medieval. En México esta tradición trascendió al renacimiento y al barroco, reteniendo de forma anacrónica una tradición tonal de carácter ascético en algunas regiones del país. Este es el caso de los órganos históricos construidos en la provincia de Oaxaca, en donde podemos cotejar prácticamente la ausencia de registros de Solo como las Cornetas, así como de algunos registros de lengüeta en chamade, los cuales al parecer no eran afines con la liturgia. Algunos de los registros de lengüeta desarrollados en número muy limitado en algunos de los órganos oaxaqueños, fueron agregados en intervenciones tardías ${ }^{7}$. Ciertamente podemos hablar, en México, e incluso en España de una consistencia estilística, pero sólo por regiones y de manera muy general y cautelosa.

Los instrumentos de tamaño significativo construidos en México, como son los de la catedral de México, los de la catedral de Puebla, e incluso aquellos de la catedral de Morelia y Guadalajara construidos por el propio Nassarre y de los cuales tenemos sólo información documental, son instrumentos que conjugan de manera consistente todas estas influencias. Estos instrumentos poseen diversos tipos de órgano pleno: Pleno de principales, pleno de flautas, pleno de lengüetas, además de una proliferación de registros de sólo: Cornetas, Clarines, Cornetas en Ecos, Tolosanas, etcétera.

Un testimonio elocuente de lo señalado lo proporciona la Gazeta de México, No. 37, de diciembre de 1730:

Guadalajara.- Ya ha hecho entrega el Maestro Don Joseph Nassarre del famoso Organo grande de la Santa Iglesia Cathedral , que finalizó este año con general honorífica aprobación de ocho de los mas científicos Sugetos en la facultad, de quienes ha merecido muchos, y muy debidos aplausos, por lo acertado de la obra, que ha tenido de costo mas de veinte mil pesos, y se compone de una muy lúcida caxa de dos fachadas de finas é incorruptibles maderas, que con sus remates toca el medio punto: proporcionado secreto de menos de 3 varas de longitud, y dos de latitud, en que artificiosamente están bien distribydas quarenta y siete canales, cerradas con otras tantas supapas y sus muelles correspondientes, con que sin desperdicio del viento, que (quatro fuelles de marca mayor que están en lo interior del Organo y lo producen de alto a baxo) ministran el necessario para dos y doscientas veintiséis flautas de que se forman sonoras y dulces mixturas, como son Flautados, Octavaz, Docenaz, Quincenaz, Decisetenas, Decinovenas, Cimbalas, Veintidocenas, ó Llenos, Nazardos, Cornetas, Trompeta Real, Bajoncillos, Clarines, Trompeta Magna, Chirimía, Oboe, vozes naturales, y sictas, todo muy bien ordenado en tono muy conveniente, el temple proporcionado, por aver observado el Autor en él la distribución, ó partición del Coma según D. Pedro Serone de Bergamo á el cap. 8, libro 21, pla 145.

7. También en España las lengüetas, sobre todo las exteriores — salvo la dulzaina — son tardías, frecuentemente ya del XVIII; de hecho, en el XVII no se las menciona en la mayor parte de los órganos importantes sino hasta muy tarde. Un artículo de don José CLIMENT en la revista Anuario Musical del año 1995 sobre "Los órganos en la Catedral de Valencia en el siglo XVII", pp.149-160, ofrece documentación de la época sobre la registración y disposición de los órganos —que serían tal vez los que pudiera haber utilizado Cabanilles_...; de modo que ahí —y se trata de una catedral metropolitana-, a mediados del XVII apenas había lengüetas, excepción hecha de las "dolçaynas"; dice Climent que "los grandes registros de lengüeta se irán añadiendo, poco a poco"; y así, en 1693, se añade al órgano mayor un juego entero de trompas reales y medio registro de clarín de mano derecha... etc. Agradezco los valiosos comentarios del Dr. Antonio Ezquerro y del Dr. Luis Antonio Gonzalez Marín del CSIC de Barcelona para la realización de este artículo.

44

(c) Consejo Superior de Investigaciones Científicas Licencia Creative Commons 3.0 España (by-nc)
Anuario Musical, 60 (2005)

http://anuariomusical.revistas.csic.es 
Esta descripción del órgano construido por Nassarre para la catedral de Guadalajara es de lo más revelador, ya que nos muestra entre otros factores importantes, y con detalle, el plan tonal que desarrollaría Nassarre en los órganos de la catedral de México cinco años más tarde. Asimismo, la información referente a la partición de la Coma pitagórica según Pedro Cerone ${ }^{8}$ en el órgano de Guadalajara, es de lo más importante en el terreno documental, lo cual comento más adelante.

Se tiene noticia de la existencia de aproximadamente ocho órganos, comparables en tamaño a los de la catedral metropolitana, construidos para diferentes catedrales en México en el siglo XVIII (Morelia, Guadalajara, Puebla, Basílica de Guadalupe, entre otras), pero solamente los de la catedral metropolitana han sobrevivido. Por ello, estos órganos son considerados entre los documentos musicales más importantes de la organería universal.

\section{Los instrumentos}

La actual catedral metropolitana de la ciudad de México, fue dedicada en 1667; sin embargo, como es bien sabido, los trabajos continuaron a lo largo de los siguientes siglos en su suntuoso y magnífico interior por lo menos hasta el siglo XIX, acumulando una fabulosa cantidad de obras de arte en los más diversos géneros y estilos.

Un documento catedralicio del 31 de mayo de 1688, registra la petición hecha por el Deán para la adquisición de un nuevo órgano proveniente de España. El documento es por demás interesante ya que contiene las especificaciones y algunas de las características que

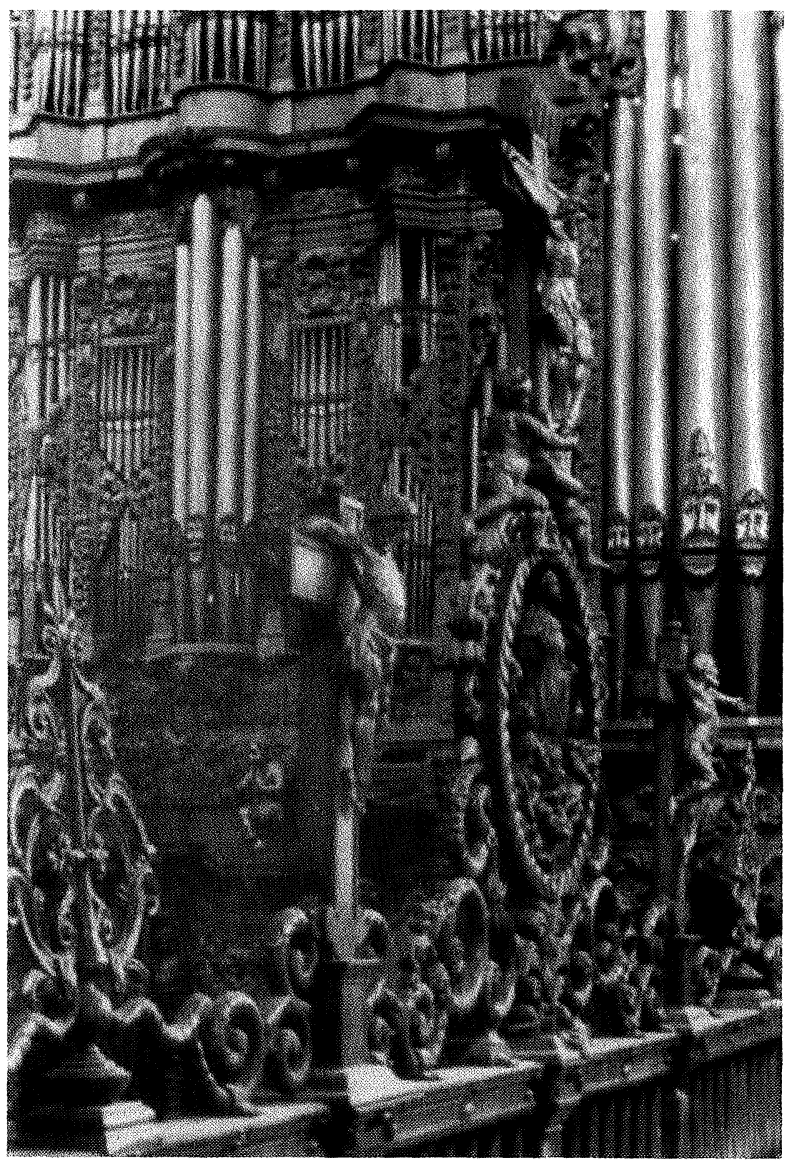

Catedral Metropolitana de México. Órgano del Evangelio, fachada del coro antes del incendio de $1967^{9}$

8. -Pedro Cerone: El Melopeo y Maestro. Nápoles, Juan Bautista Gargano y Lucrecio Nucci, 1613; hasta el momento se han podido localizar hasta tres ejemplares de este tratado conservados en la actualidad en México, síntoma inequívoco de una relativamente amplia circulación entre los músicos mexicanos de este "raro" y voluminoso tratado: en las bibliotecas del Congreso de la Unión, "Lafragua" de la Universidad de Puebla, y "Fray Francisco de Burgoa" de la Universidad Autónoma de Oaxaca. Actualmente se prepara para este año su edición facsímil, que editará el CSIC con un amplio estudio preliminar de Antonio Ezquerro.

9. Foto: Luis Márquez Romay, 1940c. 
debería de poseer el nuevo órgano: órgano principal, cadereta, y registros de pedal. Los registros que se requirieron para la composición fónica del instrumento fueron señalados de la siguiente forma:

Todos los dobles o suboctavas, para sostener un rico tono [...] [y las] acostumbradas quintas, octavas, quincenas, veintedocenas y veinticuatrocenas para obtener un tono balanceado.

Adicionalmente, se imponía un requerimiento de particular interés,

[...] cualquier novedad la cual México no haya experimentado aun, será aceptada si pasa ante el juicio de un jurado competente ${ }^{10}$.

Este requerimiento no deja de ser peculiar, si consideramos que los organeros hispánicos, pese a que nunca se mostraron reacios a la técnica y a la innovación, se mostraron tradicionalistas y conservadores en lo que se refiere a los fundamentos esenciales de la estructura del órgano. De hecho, podemos constatar a prima vista, a través de los contratos de construcción de órganos en España y México durante el siglo XVII e incluso el XVIII, que su manufactura no ofrece innovaciones notables en lo que al plan tonal se refiere. Sin embargo, es muy probable que cualquier señal de evolución se haya verificado más bien en la superficie, en el diseño general de las fachadas. De hecho, para el diseño de la caja del órgano de Sesma se sugirió tomar como modelo los órganos "modernos" de la corte española. Así pues, es evidente la importancia de mantenerse al día en cuanto a los últimos avances y desarrollos de la manufactura de órganos y la arquitectura española.

De mayor importancia documental, en relación a las prácticas musicales de la época, es un requerimiento adicional señalado para el órgano principal, que consistía en que debería ser afinado más bajo de como se acostumbraba en España, "para ajustarse al tipo de voces en el virreinato"11, mientras que la cadereta debería mantener la altura acostumbrada para acompañar instrumentos de viento sin el inconveniente de tener que transportar. Esta peculiaridad fue subrayada como esencial en los requerimientos de la catedral de México. Quizá esta fue una práctica común en Hispanoamérica para instrumentos de dos teclados; tal es el caso de los órganos de Cuzco, Perú, afinados a un intervalo de cuarta de diferencia ${ }^{12}$. Menos de cuarenta años después de la construcción del órgano de Sesma, cuando se construye el segundo órgano para la catedral a manos de Nassarre en 1735, el Deán de la catedral metropolitana pide que ambos instrumentos se pongan al unísono, lo que hace pensar que las prácticas musicales debieron sufrir importantes cambios desde un punto de vista práctico y organológico, lo que podría generar las siguientes hipótesis: 1) o bien no se había tenido en cuenta — ¿por Nassarre?... sería raro, pero no imposible... - a la hora de encargar y/o construir dicho segundo órgano, o bien, 2) que "el cabildo" - acaso por mediación del propio organero, o de algún cantor,

10. Catedral Metropolitana de México. Actas de Cabildo, Órgano del siglo XVII, tomo 62, p. 21 (31 de mayo de 1688).

11. Idem.

12. Es muy probable que estos requerimientos en la afinación estuvieran intrínsecamente vinculados al hábito de transportar una cuarta que supone el uso de claves altas. Ver lo que dice sobre ese particular por ejemplo el teórico y organista ciego aragonés fray Pablo Nassarre en su tratado Escuela Música según la práctica moderna (Zaragoza, 1723-1724); y el paralelismo con los antiguos claves flamencos de dos teclados, "transpositores".

(c) Consejo Superior de Investigaciones Científicas Licencia Creative Commons 3.0 España (by-nc)
Anuario Musical, 60 (2005)

http://anuariomusical.revistas.csic.es 
o de cualquier persona atenta e interesada en la práctica musical catedralicia cotidiana- había reparado en la necesidad "práctica e imperiosa" de ello, o bien, 3) que el cabildo hubiera reparado en la necesidad de incorporar ese "detalle" tan importante, acaso, a un contrato anteriormente acordado para la construcción de dicho segundo órgano, en el que no se hubiera hecho constar explícitamente esa cláusula...

Es oportuno comentar aquí brevemente la información de la Gazeta de México de diciembre de 1730, la cual proporciona información valiosa referente al temperamento o partición del órgano construido por Nassarre en 1730, para la catedral de Guadalajara, pues existe una gran probabilidad de que ésa haya sido la partición aplicada en los dos órganos de la catedral metropolitana de la ciudad de México cinco años después. La Gazeta señala que la partición de la Coma se hizo de acuerdo al capítulo 8. libro 21. pla[na, es decir, página] 145, de la enciclopédica obra denominada El Melopeo y Maestro de Don Pedro Cerone de Bérgamo. Pese a la poca información documental que existe sobre la afinación en los órganos novohispanos, el tema es por demás fascinante y es materia de futuras investigaciones.

El órgano de la Epístola fue construido por el maestro organero aragonés Jorge Marco de Sesma (*Zaragoza, 1655-1662; †Madrid, 22-II-1690), en Madrid [donde asentó su taller y residiría con su familia a partir de 1687 — con su mujer Margarita Ximénez, con quien se casó en 1686, y con su hijo, Juan Lorenzo José--]. Sesma provenía de una familia de organeros de Zaragoza, de la mayor tradición y reputación en la España del siglo XVII. El órgano llegó a la catedral de México, proveniente de España, el 14 de febrero de 1693 cuando Sesma había fallecido ya hacía tiempo, acompañado de un reloj y unas colgaduras. Fue instalado y completado en la catedral por Tiburcio Sans ${ }^{14}$.

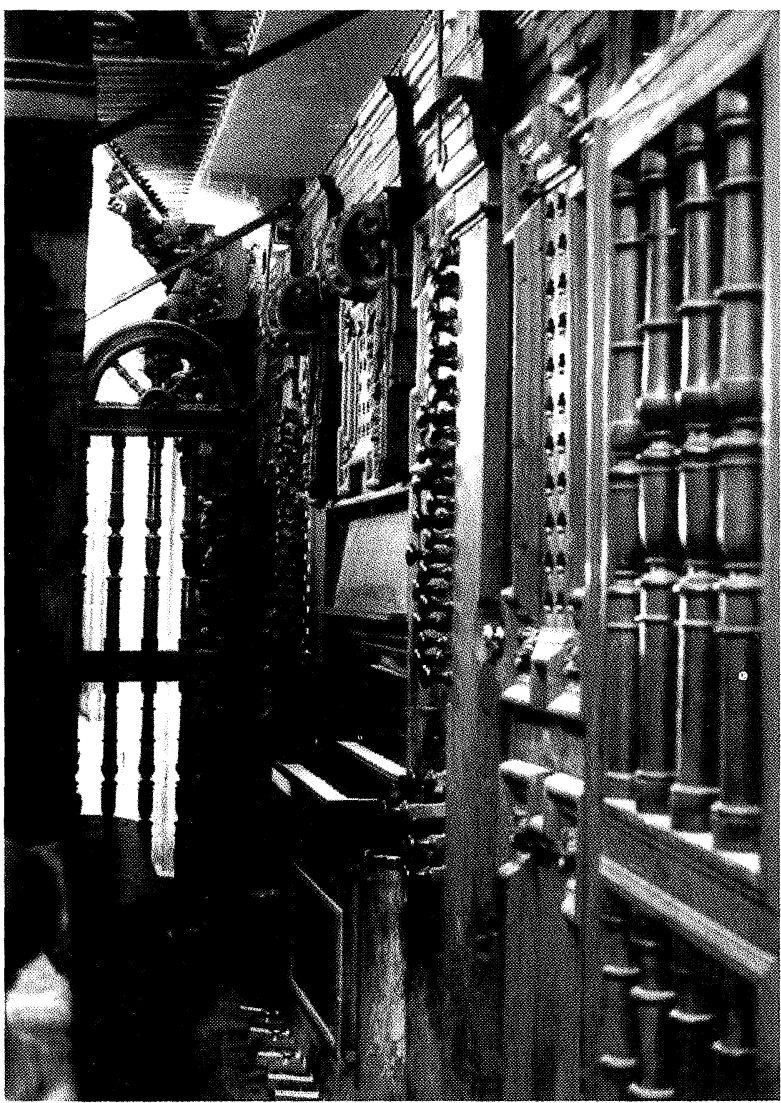

Catedral Metropolitana de México.

Consola del órgano de la Epístola después de la restauración de Flentrop ${ }^{13}$ Desde su llegada, el instrumento provocó ma-

13. Foto: Flentrop.

14. Tiburcio Sans nació en Zelda [sic. ¿"Cella", en Teruel?], Aragón, en 1652. El apellido podría leerse asimismo como "Sanz" o incluso "Saenz"; más adelante encontraremos a un organero llamado "Saenz, de Aragón". Trabajó como aprendiz de carpintería en su juventud. Posteriormente se trasladó a Málaga, donde trabajó con el escultor Francisco de Nieva. Más tarde completó su formación en Madrid en donde adquiere su formación como organero, y en donde más tarde obtendrá la comisión para instalar el órgano de la Catedral de México, para el cual además construyó un registro de Contras y 400 tubos canónicos para la fachada. 
lentendidos en el cabildo, sus miembros lo compararon con los órganos de la catedral de Puebla, pues se pretendía que este nuevo órgano los sobrepasara en tamaño y características.

[...] Los secretos estaban construidos de madera de pino y no de la calidad usada en el órgano de la catedral de Puebla, el cual tiene más de cien años y esta bueno $[\ldots]^{15}$.

Tiburcio Sans fue asistido en el montaje del órgano por su hermano Félix, la caja fue hecha por Juan de Rojas, autor también, de la magnífica sillería del coro, trabajo que realizó entre 1655 y 1697.

Antes de que el órgano de Sesma fuera oficialmente "recibido", el 15 de abril de 1695, el cabildo formó una comisión para hacer un examen del nuevo instrumento para dar por tanto su aprobación técnica definitiva de la obra recién acabada y ajustada, y formalizar así su "recepción". Los miembros de la comisión fueron Joseph de Idiaques, primer organista de la catedral; Francisco de Osuchi, segundo organista y maestro organero residente; Antonio de Salazar, maestro de capilla, entre otros expertos. Habiéndose puesto de acuerdo, el órgano fue aceptado con aprobación general. Las Actas de Cabildo de la catedral, con fecha 6 de mayo de 1695 consignan el siguiente testimonio:

Ilustrísimo Señ: El Maestro Antonio de Salazar, que lo es de esta Santa Iglesia, dice que vuestra señoría le mandó asistir a oír el órgano en su entrega, con todos los requisitos, según lo pidió su fábrica y según la memoria que de España se trajo. Halló haber cumplido con su obligación toda su artífice en las mixturas de que se compone, cada una por si y todas juntas, así en lleno como en el flautado, y según su composición sonora, dulce y armoniosa. Esto siento en mi conciencia conforme a lo que en nuestra facultad es necesario. Y por lo que toca al interior de dicho órgano, flautas, secretos, registros, fuelles, y toda su perpetuidad, me remito a lo que el artífice que los fabrica dijere. Esto digo debajo de la censura a su señoria, cuyo criado soy que besa sus manos.

Cabe señalar que pese a que el cabildo dio por recibido el órgano, el proyecto de instalación estuvo rodeado de desacuerdos y dificultades, hasta el grado de que el mismo cabildo demandó a Tiburcio Sans, supuestamente, por la ausencia de algunos registros y el resultado insatisfactorio de otros. $^{16}$

Apenas cuatro décadas después de la instalación del órgano de la Epístola, en 1734, el cabildo decidió hacer una ampliación del órgano, siendo José Nassarre, vecino de México, quien recibió la encomienda para hacer ciertos arreglos y modificaciones al órgano de la catedral que incluían la adición de una cadereta de espaldas. Las intervenciones al órgano de la catedral fueron terminadas en mayo, motivando el entusiasmo del Arzobispo, Juan Antonio de Vizarrón y Eguiarreta. Nassarre, aprovechando el éxito, presentó planes y especificaciones para la construcción de un nuevo instrumento, en lo que el arzobispo y el cabildo estuvieron de acuerdo pues habían ya planeado la donación

15. - Catedral Metropolitana de México. Actas de Cabildo, 14 de febrero de 1693.

16. Por tanto, y dado que es difícil pensar que el cabildo entendiera de estos menesteres más propiamente "técnicos", es de suponer que habría algunos expertos, posiblemente entre quienes examinaron el órgano, que habrían hallado reparos al trabajo de Sesma-Sans... 
de un segundo órgano para complementar el ya existente que se colocaría en el arco vacío de enfrente, al lado del Evangelio.

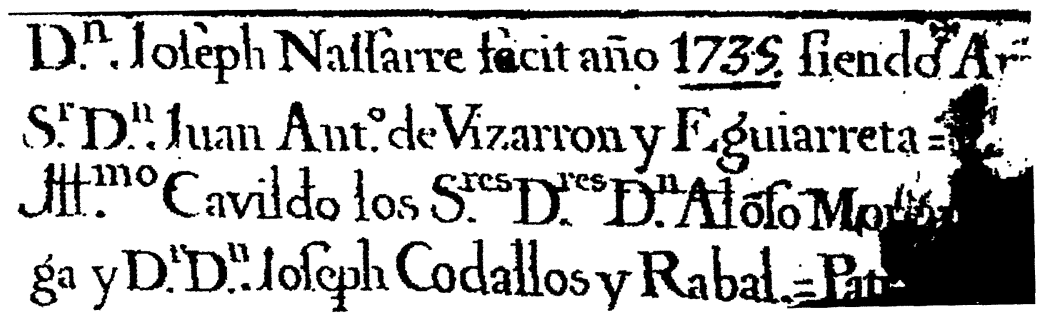

Catedral Metropolitana de México.
Inscripciones encontradas en el secreto del órgano principal del órgano de la Epístola ${ }^{17}$

En la especificación original, el nuevo instrumento debería tener

“[...] setenta y nueve mixturas, o registros [...] caja y todo lo necesario [...] hasta darlo entregado por la cantidad de treinta mil pesos y el cual ha de coger de pilar a pilar, cerrando todo el claro del arco [del lado del Evangelio] ponerle cinco fuelles secretos en el segundo cuerpo [5 fuelles en el segundo nivel]. Y que juntamente hará el antiguo, llenando todo el claro [...] y hacer la cadereta. Todo por ocho mil pesos. Item. El sr. Nassarre pondría los dos órganos al unísono en todo [cajas y flautas] por deseo del Excelentísimo Sr. Arzobispo cobrando otros diez mil pesos sobre los treinta mil ya pedidos". "Treinta meses pidió el organero para construir este segundo órgano [...]" "[...] y por el precio de los cuarenta y ocho mil, comprendiendo en esta cantidad la construcción del Órgano nuevo y de la Cadereta agregada al anterior, más el trabajo de ponerlo en consonancia [... $]^{\prime 18}$.

Cuando el arzobispo fue consultado por el cabildo acerca de las especificaciones finales, propuso que ambos órganos fueran puestos íntegramente al unísono, tanto tonalmente como en apariencia.

En el lapso de 14 meses, el órgano nuevo y la tribuna especialmente ampliada, así como su basamento en el lado del evangelio fueron completados. El órgano fue tocado por primera vez el día de la fiesta oficial de la fundación de la catedral el 15 de agosto de 1735.

La Gazeta de México, en su número 43, de agosto de 1735, consigna la siguiente nota:

[...] El 15 [de agosto] celebro la Santa Iglesia Metropolitana (erigida año de 1534) su Fiesta Titular con la solemnidad correspondiente a dia tan grande, y asistencia de S. Exc. Illma. Real Audiencia, Tribunales. Ayuntamiento, Religones, Sus Prelados, Nobleza, Y gran concurso: Haviendose estrenado a sus primeras Visperas muchas de las ochenta y seis Mixturas, de que se compone el Secreto del nuevo famoso Órgano, (que sobre la, también nueva, fornida, bien gravada Cornisa, con sus corredores,

17. Foto: Flentrop.

18. -Jesús EstradA: Música y Músicos de la Época Virreynal. México D.F, 1973, Andrés Lira SEP/Setentas, pp.42-51. Catedral Metropolitana de México. Actas de Cabildo. 
balaustres y plintos de latón finissimo, da vista a la Nave processional del lado del Evangelio) llena todo aquel buque, y empinándose sube hasta passar los términos del medio punto, ostentando por uno, y otro lado, assi lo sonoro, y suave de sus vozes, como la hermosura, y bien tallado de sus vistas; Obra que puede competir con las más sumptuosas de Europa, no quedando duda de que concluido el de enfrente, que será de igual estatura, molduras, armonía, y fachada, ya que no sus Ecos, se percebirán en lo más distante, y retirado sus aplausos [...].

Exactamente un año más tarde, el 15 de agosto de 1736, las tribunas fueron completadas, y el órgano de la Epístola, ya reconstruido, fue escuchado por primera vez, tocado alternadamente con el órgano del Evangelio, en Vísperas y en misa.

La Gazeta de México, en el número 105, de agosto de 1736, consigna lo siguiente:

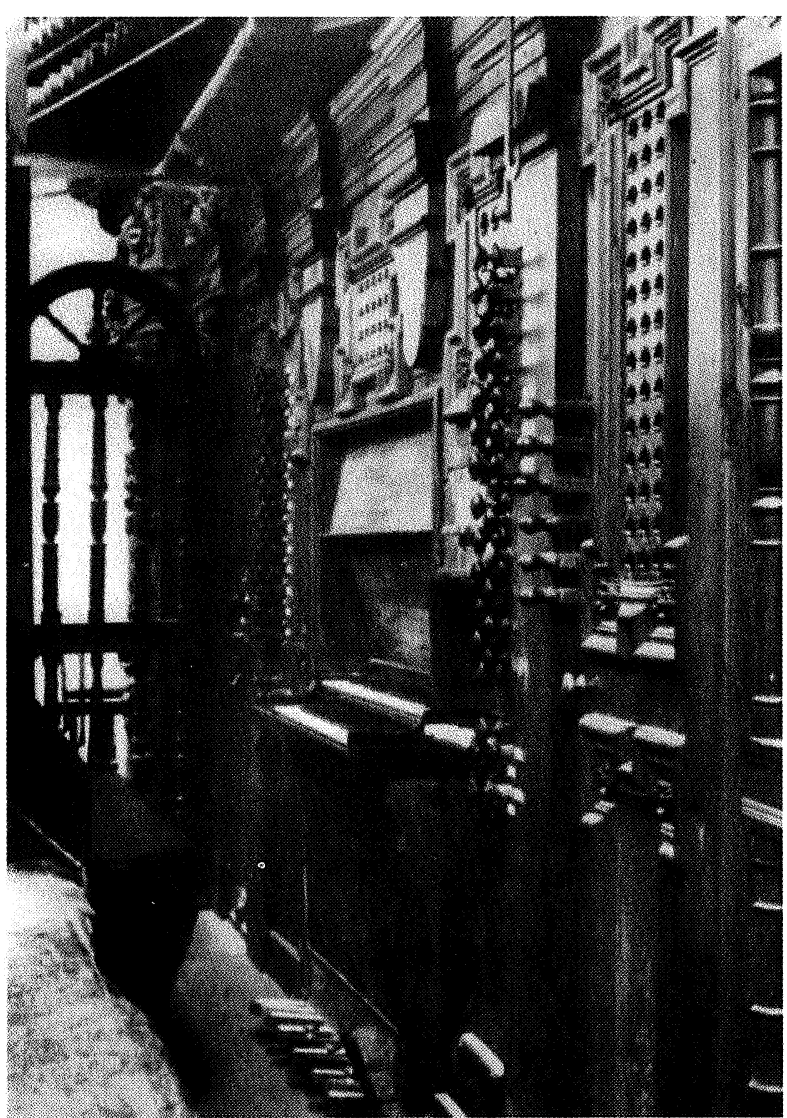

Catedral Metropolitana de México

Consola del órgano del Evangelio después de la restauración de Flentrop ${ }^{19}$

19. Foto: Flentrop.

[...] El 15 [de agosto], se estreno el exquisito, costoso, y rico ornamento entero, y palio con baras de plata, que para este dia de su Titular dio nuestro Illmo. Y Excmo. Señor Arzobispo Virrey, a su Metropolitana; en cuyo Choro quedan ya en perfeccion finalizadas las tribunas por uno y otro lado, y puesto y estrenado en el de la Epistola el otro armonioso Órgano, que en las Visperas Maytines, y en la Missa sono alternativamente con el que tiene enfrente, y se espera su entrega para para dar razón a punto fixo de su Escultura, mixturas de su composición, y de su costo [...].

Los últimos detalles del órgano de Nassarre fueron terminados por Saenz de Aragón (¿tal vez uno de los Sans o Sanz antes vistos?) en octubre de 1736, de este último no tenemos noticias por el momento. Para la recepción de los trabajos se nombró una comisión compuesta por el Maestro Manuel de Sumaya, y los tres organistas titulares de la catedral: Juan Tellez Girón, Juan Pérez Zamora y Joseph Xuárez, junto con los organistas de San Francisco y de San Agustín para recibirlo.

[...] según las condiciones de la escriptura [...] y previo el tacto pectore de decir verdad en relación con su recibo. 
La Gazeta de Mexico, número 107, del 23 de octubre de 1736, informa lo siguiente:

[...] Los días 10 y 11 [de octubre] se hizo entrega de los dos Sumptuosos Órganos de esta Metropolitana que consta cada uno de primorosa y bien tallada caxa de ricas, y exquisitas maderas, tienen diez y siete varas de alto, y onze de ancho, y haziendo asiento en la hermosa Tribuna, llenan todo aquel hueco, y suben hasta arriba del medio punto, que a este sitio corresponde: y su formal composición reduce a un capaz secreto suficiente, á que suene por ambas vistas al impelido viento, que despiden cinco Fuelles de marca mayor, que lo comunican de alto á baxo, sin ser vistos, ni oídos, por ser contenidos en lo interior, y más alto de las Caxas, que son tan corpulentas, que cada una encierra en lo interior, y en sus fachadas tres mil trescientas y más de cincuenta Flautas, de que se forman las armoniosas mixturas de Flautados llenos. Cornetas, Trompetas, Clarines, Nasardos, Ecos, Tambores, Campanas, Cascabeles, Violines, Bajonzillos, y todo lo demás que constituye un órgano, con todos sus cabales.

Los instrumentos ya completados cubrieron todas las expectativas, tal como lo había prometido Nassarre. Los órganos completaron la armonía arquitectónica interior de la catedral con cuatro de las fachadas más impresionantes en la historia universal del órgano barroco.

Sobre el lado del coro, hay 159 flautas parlantes en la fachada de cada instrumento, incluyendo la cadereta, en cuyo prospecto de fachada se distribuye la Octava clara 4' del bajo, las grandes torres de 16' del Flautado del Pedal ubicadas a los costados de las fachadas del coro, y la primera hilera de flautas en la fachada central pertenecientes al Flautado mayor de 8' del Organo Mayor.

Las cajas de las caderetas poseen una torre central redonda con campos planos descendentes a cada lado con el siguiente prospecto: $8-5-8$.

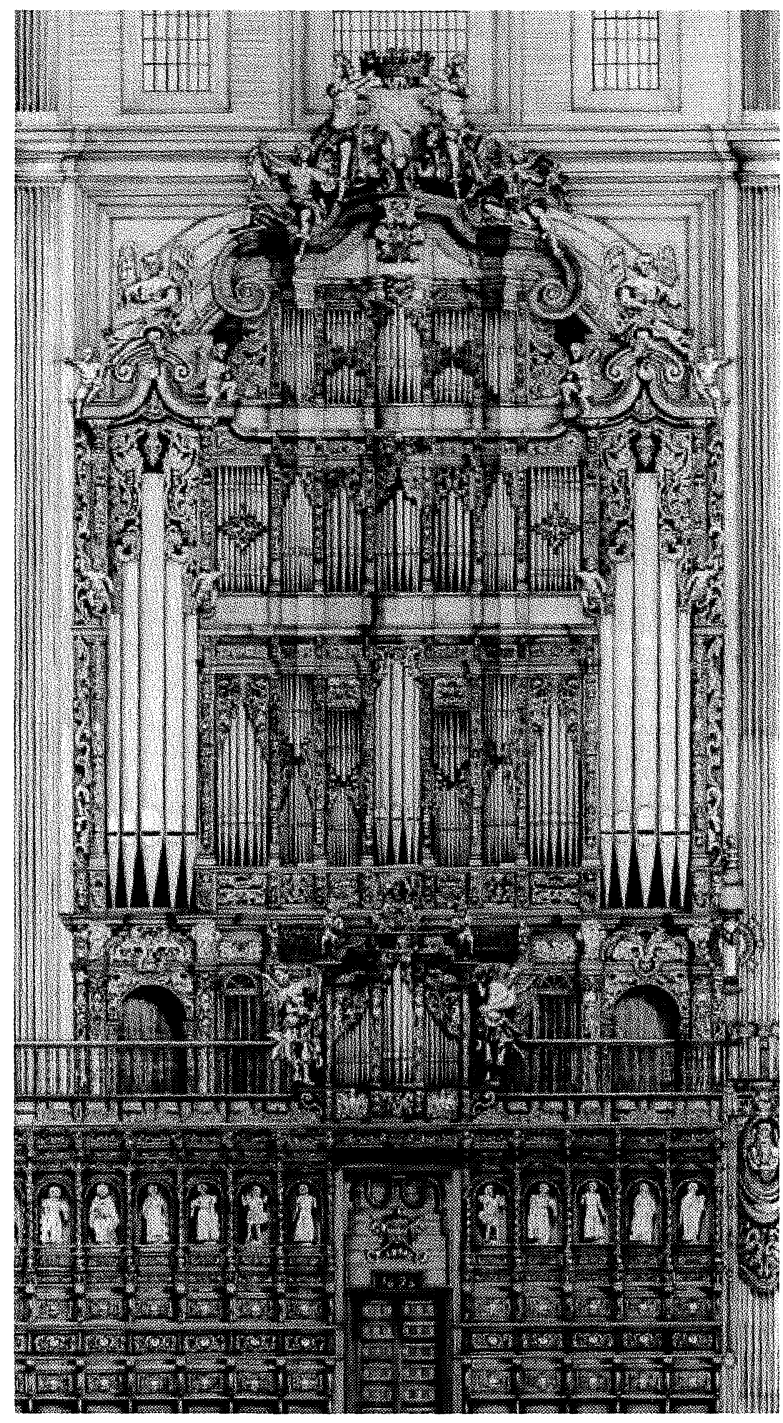

Catedral Metropolitana de México Órgano del Evangelio, fachada del coro ${ }^{20}$

20. Dibujo de S. Schaper, Flentrop. 
Las majestuosas torres del pedal que contienen las 10 flautas del registro de Flautado de 16' se curvan ligeramente, llevando al cuerpo principal de la fachada de los órganos hacia el plano arquitectónico de los arcos, en los cuales los órganos se insertan.

El diseño de las fachadas a través de campos planos, torres en forma de "v", torres redondas y flautas invertidas en el centro de la fachada, sugieren una influencia de los diseños flamencos y neerlandeses del siglo XVII, asimilados a una manera típicamente Iberoamericana.

Las hileras de flautas segunda y tercera de las fachadas del coro, así como las flautas colocadas en espejo, son tubos canónicos: hablamos de 147 flautas mudas en cada fachada (147 x 2 fachadas $=294$ tubos canónicos).

Las fachadas exteriores (lado de la nave) contienen sólo dos hileras de flautas parlantes las cuales están situadas en la parte inferior: Flautado mayor de 8' órgano principal, y Flautado de 8' y 4' del pedal.

Colocada sobre las fachadas del coro, justo arriba de la consola de cada órgano se encuentra la trompetería horizontal. El órgano del Evangelio tiene en la fachada de la nave, tres registros para el bajo y tres para el tiple, el órgano de la Epístola tiene también tres registros para el bajo y tres para el tiple.

Las fachadas exteriores son similares a aquellas del coro, excepto por las torres de 16' del pedal de los costados, y desde luego sin las caderetas. Desde el piso de la catedral, su magnificencia es rematada por su ubicación en las majestuosas tribunas, sostenidas por robustos pilares.

El órgano de la Epístola podría contener elementos del órgano de Sesma de 1695, pero éstos son difíciles de identificar. Según testimonio de Dirk Flentrop, después de un detallado examen de ambos instrumentos durante la restauración realizada por él mismo entre 1975-1977, y una estricta interpretación de toda la documentación existente, indica que los trabajos de Nassarre implicaron una casi total reconstrucción del órgano de Sesma.

Es muy probable que estos maravillosos instrumentos, hayan ejercido una influencia como modelos para la construcción de los órganos españoles de la catedral de Granada construidos por Leonardo Fernández Dávila y los de Málaga hechos por Julián de la Orden; la concepción musical de la composición y plan de los registros, obedecen casi al mismo proyecto y distribución que los de la catedral metropolitana. Estos instrumentos poseen dos teclados, el de Nassarre dos y medio, sin embargo cada uno contiene cuatro divisiones y media. Cada uno posee una cadereta interior y una exterior operables a través del primer teclado. Ambas divisiones son dependientes una de la otra y conforman una unidad tonal. La cadereta de espaldas contiene los registros agudos y una corneta. La cadereta interior colocada en la parte inferior de la caja principal, es una división de mayor tamaño con registros de $8^{\prime}$ que incluyen el Violón, el Bajoncillo, el Flautado Mayor (tiple,) entre otros. Esta es la distribución en términos generales empleada por Fernández Dávila y Julián de la Orden. El Organo Mayor del órgano del Evangelio contiene 58 medios registros, el de la Epistola 52. Sin lugar a dudas se trata de los prospectos fónicos de mayor tamaño operables desde un manual en relación a cualquier instrumento de estética clásica ibérica conocido hasta hoy.

52

(c) Consejo Superior de Investigaciones Científicas Licencia Creative Commons 3.0 España (by-nc)
Anuario Musical, 60 (2005)

http://anuariomusical.revistas.csic.es 
El órgano de la Epístola (Sesma, 1695)

El órgano de la Epístola consiste de las siguientes divisiones:

- La Cadereta: Operada por el primer teclado. La cadereta se divide en cadereta interior colocada en la parte inferior de la caja del órgano, justo detrás de la consola y la cadereta de espaldas u órgano positivo. La cadereta de espaldas carece de registros fundamentales (8') y solamente posee registros a partir de la Octava (4'), razón por la cual casi siempre se utiliza combinada con la cadereta interior (ambas se tocan desde el mismo teclado), que posee los registros fundamentales (Violón 8', entre otros).

- Órgano mayor: Operado a través del segundo teclado y repartido en cuatro secretos, dos para el bajo y dos para el tiple.

- Pedal: Dispuesto en dos secretos colocados transversalmente al interior de la caja del órgano.

Los tiradores de los registros están colocados a los costados derecho (tiple) e izquierdo (bajo) del marco de la consola. Las filas superiores corresponden al órgano mayor y las inferiores a la cadereta interior. Los tiradores de la cadereta de espaldas están colocados a espaldas del organista.

Los registros labiales del pedal siempre están en posición abierta, pues no poseen tiradores. Para los registros de lengüeta del pedal (contras) existen dos tiradores de metal, correspondientes a los dos secretos.

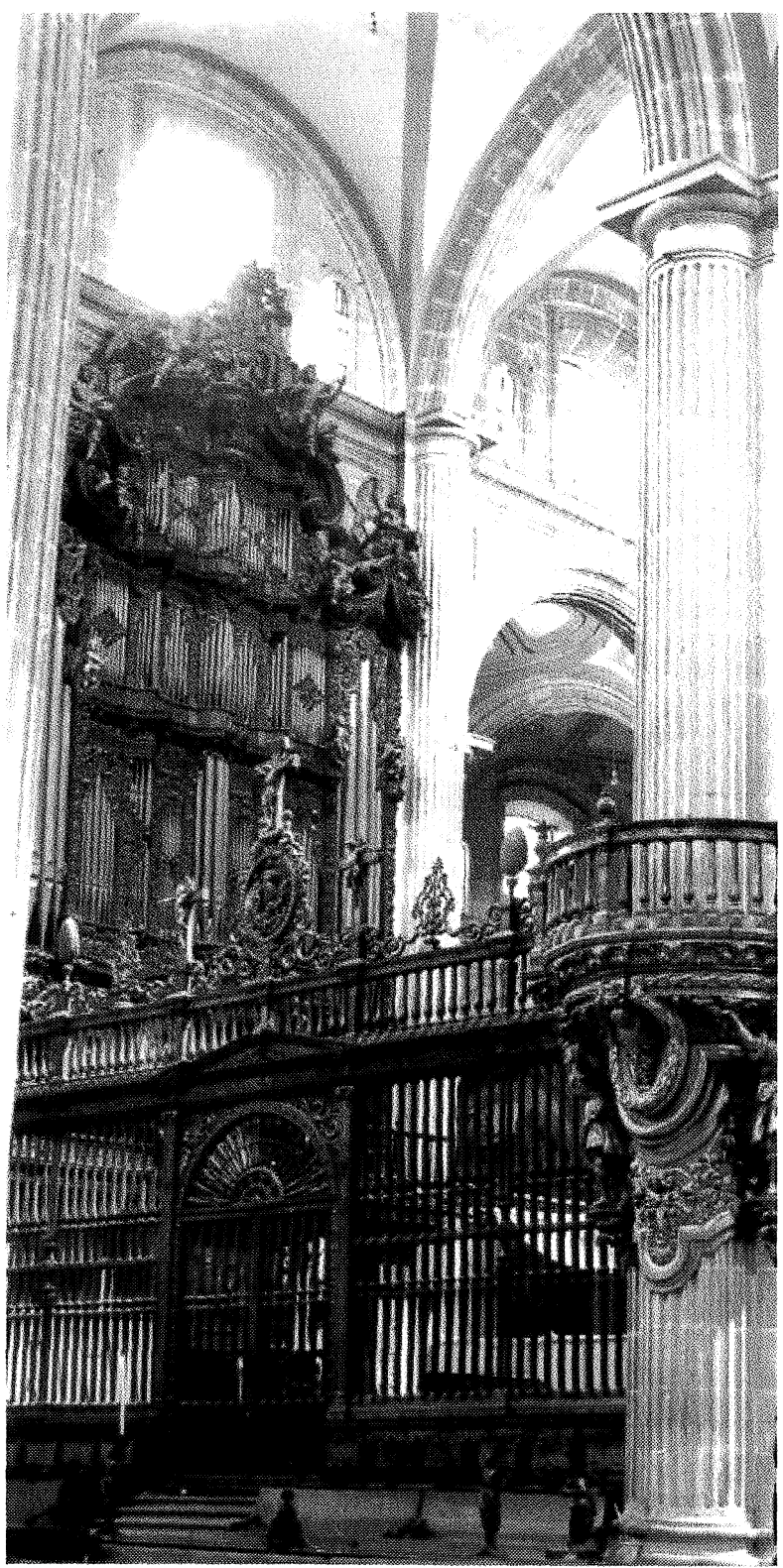

Catedral Metropolitana de México Órgano de la Epístola, fachada del coro después de la restauración de Flentrop ${ }^{21}$

21. Foto: Flentrop. 
Para los registros de Clarín Claro (bajo y tiple) de la fachada del coro, hay dos palancas de hierro forjado para operarlos. Los registros de la cadereta de espaldas poseen palancas de hierro para ser accionados.

El mecanismo de la cadereta está compuesto por un secreto colocado debajo del primer teclado sobre el piso de la galería, y es operado mecánicamente a través de tirantes de madera conectados al primer teclado. El secreto está conectado a la cadereta exterior a través de conductos de viento tallados directamente en un bloque de madera masiva.

Todos los secretos del órgano de la Epístola son de disposición enteramente cromática.

\section{Disposición del órgano de la Epístola}

REGISTROS BAJOS

\section{REGISTROS ALTOS}

\section{Órgano Mayor: Segundo teclado}

Do-do' (25 notas)

Flautado mayor

Flautado nave

Violón

Octava clara

Octava nazarda

Fabiolete

Espigueta

Docena clara

Docena nazarda

Quincena clara

Quincena nazarda

Diez y setena clara

Diez y setena nazarda

Diez y novena clara

Veinte docena clara

Corneta de eco

Lleno

Símbala

Sobre símbala

Tolosana

Chirimía nave

Bajoncillo

Trompeta real

Bajoncillo

Clarín en quincena

Orlo do\#-re"" (26 notas)

Flautado de 26

Flautado mayor

Flautado nave

Violón

Octava clara

Octava nazarda

Flauta traversa

Espigueta

Docena clara

Docena nazarda

Quincena clara

Quincena nazarda

Diez y setena clara

Diez y setena nazarda

Diez y novena clara

Corneta magna

Corneta de eco

Lleno

Símbala

Sobre símbala

Trompeta magna

Clarín claro

Clarín claro

Clarín claro

Trompeta magna

Chirimía 
Clarín en quincena Obue

Obue

Trompa real

Clarín claro

Cadereta interior: Primer Teclado

Octava clara

Docena clara

Diez y setena

Diez y novena

Lleno

Violón

Violón
Flautado mayor

Octava clara

Docena clara

Tolosana

Corneta de ecos

Lleno

Cadereta de espaldas: Primer Teclado

Octava clara

Quincena clara

Veinte docena
Fabiolete

Quincena clara

Diez y setena clara

Corneta magna

\section{Cambios sufridos en la disposición del órgano de la Epístola}

A través del análisis de la superficie de los secretos es posible observar que la disposición original fue ligeramente alterada en el siglo XIX, pues aún se conservan los orificios en la mesa del secreto; estas huellas dan testimonio del tipo de composición de los registros que fueron eliminados. De acuerdo a Dirk Flentrop las alteraciones son las siguientes:

\section{ÓRGANO MAYOR}

Símbala (2 filas, bajo)

Sobre símbala (3 filas, bajo)

Símbala (3 filas, tiple)

Sobre símbala (2 filas, tiple) originalmente un registro de una fila originalmente un registro de una fila originalmente un registro de 4 filas originalmente un registro de 3 filas

Como puede observarse, la composición de las mixturas fue alterada sustancialmente, de tal forma que en la actualidad no es posible coronar el órgano pleno con cualquiera de las mixturas (Lleno, Símbala, Sobre símbala), ya que fueron modificadas en su composición a manera de registros partidos (las mixturas de la mano derecha siempre son más graves que las de la izquierda). Esta condición hace imposible su empleo en la ejecución de música polifónica. 


\section{Equivalencia en nomenclatura internacional de la disposición del órgano de Sesma y breve des- cripción de sus registros}

\section{Cadereta de espalda}

\section{REGISTROS BAJOS}

Do-do'

Octava clara

Quincena clara

Veinte y docena clara

Fabiolete

Quincena clara

Diez y setena clara

Corneta magna

\author{
REGISTROS ALTOS \\ do\#'-re","
}

\section{CAdereta INTERIOR}

\section{REGISTROS BAJOS \\ Do-do'}

Violón

Octava clara

Docena clara

Diez y setena clara

Diez y novena clara

Tolosana

Lleno

Lleno

Bajoncillo

\section{REGISTROS ALTOS \\ do\#'-re','}

Flautado mayor

Violón

Octava clara

Docena clara
Corneta de 5 filas, espiga 8', 4' -22/3' - 2 - 13/5'

4' octava, flautas de fachada

4' flauta cónica

2' octava

1 ' octava

2' - $13 / 5$ ' registro de 2 filas
8 ' principal

8 ' flauta tapada de metal

4' Octava

22/3' escala del principal

$13 / 5$ ' escala del principal

$11 / 3$ ' escala del principal

Registro de 3 filas, escala del principal: 22/3' - 2' - $13 / 5$ '

Mixtura de 3 filas

4' trompeta

8 ' trompeta

\section{ÓRgano MAYOR}

\section{REGISTROS BAJOS \\ DO-do' \\ Orlo \\ Bajoncillo \\ Clarín en quincena \\ Trompeta magna \\ fachada coro}

Clarín claro

Flautado mayor

\section{REGISTROS ALTOS do\#'-re",'}

16 ' trompeta horizontal,

\section{Chirimía \\ Clarín claro \\ Clarín claro}

Obue

Flautado de 26

Flautado mayor
4' trompeta horizontal, fachada coro 4' trompeta horizontal, fachada coro 2' trompeta horizontal, fachada coro

16' oboe horizontal, fachada coro 4' trompeta horizontal, fachada coro 8 ' trompeta horizontal, fachada coro 8 ' trompeta horizontal, fachada coro 8 ' oboe horizontal, fachada coro 16 ' madera 8' principal, fachada del coro 
Flautado mayor

Violón

Octava clara

Octava nazarda

Docena clara

Docena nazarda

Fabiolete

Quincena clara

Quincena nazarda

Espigueta

Diez y setena clara

Diez y setena nazarda

Diez y novena clara

Veinte y docena clara
Flauta traversa

Violón

Octava clara

Octava nazarda

Espigueta

Docena clara

Docena nasarda

Quincena clara

Quincena nazarda

Diez y setena clara

Diez y setena nazarda

Diez y novena clara

Corneta magna

Corneta ecos

Tolosana

Lleno

Símbala

Sobre símbala

Trompa real

Flautado mayor

Bajoncillo

Clarín claro

Obue
Lleno

Símbala

Sobre símbala

Trompa real

Flautado mayor

Trompa magna

Clarín claro

Obue
8 ' registro de madera

8 ' registro de 2 filas, madera, ondulante

8 ' flauta tapada, metal

4' octava

4' flauta tapada

4' espigueta

$22 / 3$ ' escala del principal

$22 / 3$ ' flauta tapada

22/3' flauta cónica

2' octava

2' flauta tapada

2 ' espiga

$13 / 5$ ' escala del principal

$13 / 5$ ' flauta tapada

$11 / 3$ ' escala del principal

1 ' octava

Corneta de 7 filas: 8' espiga - 4' - 22/3' - 2' - 2' - 13/5' - 13/5'

Corneta de 7 filas, en caja de ecos, misma composición de la anterior

Registro de 3 filas, escala del Principal: 3 1/5' - 22/3'-1 1/3'

Mixtura de 5 filas con $2 / 5$ ' en el bajo y $13 / 5$ ' en el agudo

Mixtura 3 filas

Mixtura 2 de filas: $13 / 5^{\prime}$ en el agudo

8 ' trompeta interior

8 ' principal, fachada nave

Registro cancelado

8' trompeta horizontal, nave

4' oboe horizontal, nave

16 ' trompeta horizontal nave

8 ' trompeta horizontal, nave

8 ' oboe, horizontal nave

\section{Pedal}

DO, RE, MI, FA, FA\#, SOL, SOL\#, LA, SIb, SI

Flautado (Contras 16', 8', 4')

16' registro de 2 filas, una de metal, colocada en la fachada del coro, la otra de madera. 8' y 4' en metal.

Bajoncillo (Contras 16', 8', 4')

Lengüetas de 16', 8', 4' con resonadores de madera 
Sistema de alimentación de aire: dos grandes fuelles cuneiformes de tipo reserva, colocados en lo alto del órgano. Los dos fuelles son operados en forma alternada por una palanca a manera de péndulo. Los fuelles grandes poseen 8 folios, mientras que los alimentarios poseen dos.

Presión del aire: $75 \mathrm{~mm}$.

Diapasón: la'-415.

Temperamento: Chaumont.

\section{EI Órgano del Evangelio (Nassarre, 1735)}

El órgano del Evangelio consiste en las siguientes divisiones:

- La cadereta: Operada a través del primer teclado y dividida en cadereta de espaldas y cadereta interior.

- Órgano Mayor: Operado a través del segundo teclado y distribuido en 4 secretos, dos para el bajo y dos para el tiple.

- Recitativo (solo): Operado a través de un pequeño tercer teclado de dos octavas, ubicado en el extremo derecho de la consola. Esta división se encuentra comple-

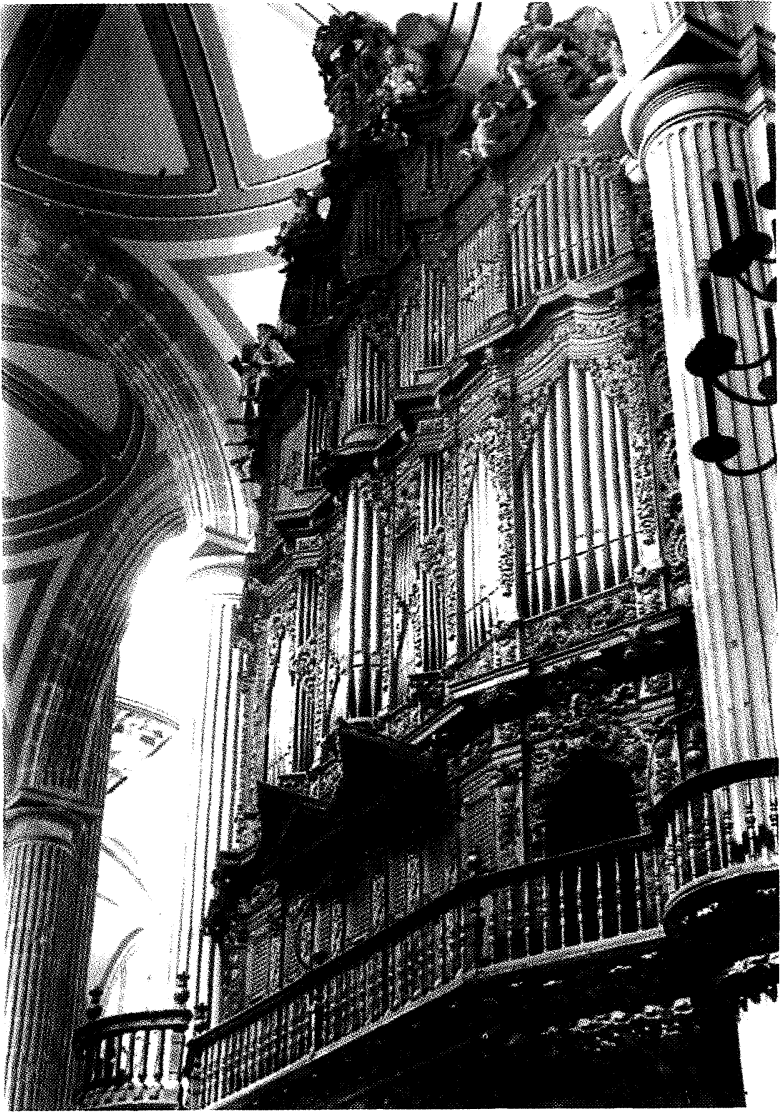

Catedral Metropolitana de México Órgano del Evangelio,

fachada de la nave después de la restauración ${ }^{22}$ tamente al interior de una caja de Ecos.

- Pedal: Distribuido en dos secretos colocados transversalmente a los costados izquierdo y derecho de la parte baja de la caja del órgano.

Las flautas del pedal (contras), también pueden ser operadas manualmente a través de una contraoctava dispuesta en el órgano mayor.

\section{Compás de los teclados:}

Primer teclado (cadereta): Do, Re-re",

Segundo teclado (órgano mayor): Contraoctava DODO, RERE, MIMI, FAFA, FAFA\#, SOLSOL, SOLSOL\#, LALA, SISIb, SISI, Do, Re-re"”,

22. Foto: Flentrop. 
Tercer teclado (solo): do'-re","

Pedal: DO, RE, MI-SI

Los tiradores de los registros están colocados en dobles hileras al lado izquierdo (registros bajos) y derecho (registros altos) del marco de la consola. Las hileras superiores corresponden al órgano mayor, las inferiores a la cadereta. Hay una fila independiente para los registros del teclado de solo al lado derecho de los registros del órgano mayor.

Todos los secretos del órgano del Evangelio son de disposición enteramente cromática.

\section{DISPOSICIÓN DEL ÓRGANO DEL EVANGELIO}

\section{REGISTROS BAJOS}

\section{SEGUNDO TECLADO}

Do, Re-do' (25 notas)

Flautado de 26

Flautado mayor

Flautado nave

Violón

Octava clara

Octava nazarda

Espigueta

Docena nazarda

Docena clara

Espigueta

Quincena clara

Quincena nazarda

Diez y setena nazarda

Diez y novena clara

Veinte docena clara

Veinte docena nazarda

Lleno

Símbala

Sobre símbala

Orlo

Trompeta real

Bajoncillo
REGISTROS ALTOS

do\#-re", (26 notas)

Flautado de 26

Flautado mayor

Flautado nave

Violón

Octava clara

Octava nazarda

Espigueta

Docena nazarda

Docena clara

Flauta traversa

Quincena clara

Quincena nazarda

Diez y setena clara

Diez y setena nazarda

Diez y novena clara

Rochela

Corneta magna

Corneta de ecos

Lleno

Símbala

Sobre símbala

Tolosana

Trompeta magna

Trompeta magna

Trompeta real

Clarín claro 
$\begin{array}{ll}\text { Bajoncillo } & \text { Clarín claro } \\ \text { Clarín de quincena } & \text { Clarín claro } \\ \text { Orlo } & \text { Obue } \\ \text { Chirimía } & \text { Chirimía }\end{array}$

Cadereta interior: Primer Teclado

Trompeta

Violón

Octava clara

Veinte docena

Diez y setena

Diez y novena

Lleno
Trompeta

Violón

Octava nazarda

Docena clara

Diez y setena

Tolosana

Lleno

\section{Cadereta de espalda: Primer Teclado}

Octava clara

Quincena clara

Veinte docena clara
Octava clara

Quincena clara

Diez y novena

Corneta magna

\section{ReCitativo de MANo DeRECHA: TERCER TEClado EN CAJA DE EXPRESIÓN}

Teclado do-re"', (27 notas)

Violines

Chirimía

Violón

Docena clara

Quincena clara

Diez y novena clara

\section{Algunos cambios sufridos en la disposición del órgano del Evangelio}

Nuevamente a través del análisis de la superficie de los secretos ha sido posible observar que la disposición original fue ligeramente alterada en el siglo XIX. De acuerdo con Dirk Flentrop ${ }^{23}$ las alteraciones en el órgano del Evangelio son las siguientes:

23. Dirk A. Flentrop, documentos. Este artículo está escrito a partir de documentos facilitados directamente de la mano de Dirk A. Flentrop (*Zaandam 1-mayo-1910; † Zaandam 30-noviembre-2003). La mayor parte de las fotografías aquí utilizadas me fueron proporcionadas gracias a la generosidad de este gran organero neerlandés. En la década de 1990 tuve el privilegio de entablar una fructífera amistad con el Sr. Flentrop, habiendo tenido la oportunidad de discutir numerosos temas relacionados con la restauración de los órganos históricos de la catedral de México y temas afines. 


\section{ÓRgANo MAYOR}

Símbala (registro de 3 filas, bajo)

Sobre símbala (registro de 2 filas, bajo)

Símbala (registro de 2 filas, tiple)

Sobre símbala (registro de 3 filas, tiple)

\section{Cadereta de espaldas}

Veinte y docena clara (bajo)

\section{Cadereta inTerior}

Lleno (registro de 3 filas, bajo)

Lleno (registro de 3 filas, tiple)

Espacio abierto en bajo y tiple

Tercer teclado (SOLO)

Docena clara originalmente un registro de 4 filas originalmente un registro de 3 filas originalmente un registro de 3 filas originalmente un registro de 4 filas

originalmente registro de 3 filas

originalmente un registro de 4 filas originalmente un registro de 5 filas originalmente un registro de lengüeta

originalmente un registro de 2 filas

Equivalencia en nomenclatura internacional de la disposición del órgano de Nassarre y breve descripción de sus registros

\section{CADEReta DE ESPALDA}

REGISTROS BAJOS

DO, Re-do'

Octava clara

Quincena clara

Veinte y docena clara

REGISTROS ALTOS

DO\#'-RE','

Corneta magna

Octava clara

Quincena clara

Diez y novena clara

\section{CADERETA INTERIOR}

REGISTROS BAJOS

Do, Re-do'

Lleno

Veinte y docena clara

Diez y novena clara
Octava 4', parcialmente colocada en la fachada

Octava 2'

Octava 1'

Corneta de 5 filas

8' Espiga, complementada con tubos abiertos.

$8^{\prime}-4^{\prime}-22 / 3^{\prime}-2$ ' - $13 / 5^{\prime}$

4' octava

2' octava

$11 / 3^{\prime}$, de la escala del Principal 
Diez y setena clara

Octava Nasarda

Violón

REGISTROS ALTOS

do\#'-re",

Tolosana

Registro cancelado

Lleno

Diez y setena clara

Docena clara

Octava nasarda

Violón

Flautado mayor

ÓRgano MAYOR

REGISTROS BAJOS del primer secreto

Do, Re-do'

Bajoncillo

Clarín quincena

Orlo

Flautado mayor

Flautado de 26

Violón

Octava clara

Octava nasarda

Docena clara

Docena nasarda

Quincena nasarda

Diez y setena nasarda

Espigueta

REGISTROS BAJOS del segundo secreto:

Trompa real

Quincena clara

Diez y novena clara

Espigueta

Veinte y docena nasarda

Veinte y docena clara

Lleno

Símbala

Sobre símbala

Flautado mayor

Chirimía

Clarín claro

Clarín quincena
$13 / 5^{\prime}$, escala del principal

4', flauta abierta

8 , flauta tapada

Registro de 3 filas de la familia del principal

Constituido como sigue: $31 / 5^{\prime}-22 / 3^{\prime}-2$ '

(probablemente espacio para un registro de escala amplia)

Mixtura de 3 filas

$13 / 5^{\prime}$ de la escala del principal

$22 / 3$ ' de la escala del principal

4 ' flauta abierta

8 ' flauta tapada

8 ' principal

4' trompeta horizontal

2' trompeta horizontal

4' trompeta horizontal

8 ' principal colocado en la fachada del coro

16' bourdón 16' (madera)

8 ' flauta tapada (metal)

4' octava

4' flauta abierta

$22 / 3^{\prime}$ escala del principal

$22 / 3$ ' flauta abierta

2 ' flauta abierta

$13 / 5$ ' flauta abierta

4' espigueta

8 ' trompeta

2' octava

$11 / 3^{\prime}$ escala del principal

2 ' espigueta

1 ' flauta abierta

1' octava

Mixtura de 5 filas

Mixtura de 3 filas

Mixtura de 2 filas

8 ' principal, fachada del lado de la nave

4' oboe horizontal del lado de la nave

4' trompeta horizontal del lado de la nave

2 ' trompeta horizontal del lado de la nave
62

(c) Consejo Superior de Investigaciones Científicas Licencia Creative Commons 3.0 España (by-nc) 
REGISTROS ALTOS del primer secreto:

do\#'-re',"

Clarín claro

8' trompeta horizontal

Clarín de campana

Clarín de campana

8 ' trompeta horizontal

8 ' trompeta horizontal

(Ambos clarines son casi de la misma escala, el Cla rín

Obue

Chirimía

claro posee resonadores de escala más grande)

8 ' oboe horizontal

Trompa magna

16 ' oboe horizontal

Flautado mayor

16 ' trompeta, horizontal

Trompa real

Corneta magna

8 ' principal fachada del coro

8 ' trompeta

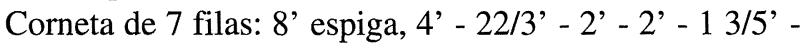

Violón

Octava nazarda

$13 / 5$ ' esta última abierta.

8 ' flauta tapada

4' flauta tapada

Docena nazarda

22/3' flauta tapada

Docena nazarda

22/3' flauta tapada

(La diferencia en la segunda Docena es que la boca es más ancha)

Quincena nazarda

2' flauta tapada

Diez y setena nazarda

$13 / 5^{\prime}$ flauta tapada

Diez y novena nazarda

$11 / 3$ ' flauta tapada

Corneta ecos

Corneta de 7 filas, montada en un secretillo al interior de una caja de ecos, operable a través de un pedal. La composición de la corneta es: 8' espiga - 4' - 22/3' - 2' - 2' $13 / 5^{\prime}-13 / 5^{\prime}$

REGISTROS ALTOS del segundo secreto:

Flauta travesera

$8^{\prime}$, registro de 2 filas, tubos de madera abiertos, registro ondulante

\section{Espigueta}

Tolosana

4' espiga

Registro de 3 filas de la familia del principal $31 / 5^{\prime}-2$ 2/3' - 2'

Octava clara

4' escala del principal

Docena clara

2 2/3' escala del principal

Quincena clara

2' escala del principal

Diez y novena clara

$11 / 3$ ' escala del principal

Lleno

Mixtura de 5 filas (con $13 / 5^{\prime}$ )

Sobre símbala

Símbala

Flautado de 26

Mixtura de 3 filas (con 13/5')

Mixtura de 2 filas

16 ' bourdon (madera)

Flautado mayor

Bajoncillo

Clarín claro

8 ' principal, fachada del lado de la nave

16 ' trompeta horizontal, lado de la nave

8 ' trompeta horizontal, lado de la nave

Obue

8 ' oboe horizontal, lado de la nave 


\section{Órgano Recitativo}

TERCER TECLAdo (mano derecha), colocado en caja de ecos

do'-re','

Violón

Chirimía

Docena clara

Quincena clara

Diez y novena clara

Violones
8' flauta tapada de metal

16 ' oboe

$22 / 3$ ' de la escala del principal

2 ' de la escala del principal

$11 / 3$ ' de la escala del principal

8' registro de lengüeta con resonadores de trompeta de escala angosta

Pedal: DO, RE, MI, FA, FA\#, SOL, SOL\#, LA, Sib, SI

Flautado (contras)

16' abierto, dispuesto en la fachada del coro, 8' y 4' abiertos, colocados en la fachada de la nave. Algunos tubos al interior.

Bajoncillos (contras)

Registros de lengüieta de 16', 8' y 4' con resonadores de madera

Sistema de alimentación de aire: 6 fuelles cuneiformes con seis 6 folios cada uno.

Presión del aire: $95 \mathrm{~mm}$.

Diapasón: la' = $415 \mathrm{~Hz}$.

Temperamento: Chaumont.

\section{Breve análisis del estado actual de los órganos}

Como ya se mencionó, estos instrumentos fueron un tanto modificados a lo largo de los siglos en su estructura general, algunas de tales modificaciones alteraron el carácter original de los instrumentos. Esas modificaciones se hacen evidentes al examinarlos cuidadosamente. Sin embargo, estos órganos, en el sentido arqueológico de la palabra, se encuentran en un excepcional estado de conservación.

Desafortunadamente, algunos daños han deteriorado seriamente a los órganos durante la segunda mitad del siglo XX. Primero, el incendio ocurrido en la catedral en la década de 1960 alcanzó a los órganos, habiéndose perdido entre otros daños, las flautas de fachada y las de las caderetas exteriores. Otros factores como las filtraciones de agua y la humedad excesiva, así como el exceso de polvo acumulado debido a los trabajos de restauración que se realizaron en la catedral desde hace algunos años, son también factores importantes del deterioro, ocasionando daños a las flautas y, de manera más general, a las partes mecánicas y a los secretos.

Después de haber tocado con mucha atención los dos órganos, especialmente el de la "Epístola", resulta evidente que semejantes instrumentos tan monumentales producen actualmente un sonido extremadamente débil, si tomamos en consideración la enorme cantidad de elementos que nos asegu- 
ran que ambos instrumentos fueron concebidos para llenar los grandes espacios de la catedral y para ocasionar una gran impresión entre los feligreses.

No cabe duda que la gran cantidad de polvo y la humedad excesiva en la catedral son responsables en parte de esta situación, pero en realidad, el problema ya existía desde antes, probablemente desde principios del siglo XX. Sin embargo, la restauración realizada por Flentrop tuvo que respetar esas condiciones y sujetarse a la situación en la cual los órganos fueron conservados: en este sentido, los trabajos realizados por la firma holandesa fueron fieles, prudentes y de excelente calidad, de acuerdo a los parámetros internacionales de la organería de los años setenta. Todo parece indicar que no se realizaron intervenciones irreversibles, sin embargo la decisión de restaurar las flautas al estado en que fueron encontradas (estado derivado principalmente de las intervenciones realizadas en el siglo XIX), deja al organista y al escucha a la espera de un sonido más afirmado desde un punto de vista histórico y en consonancia a la estética y estilo barroco (recordemos la modificación de la composición de las mixturas en el siglo XIX, entre otras).

Ésta es la razón por la cual hoy se requiere de un profundo análisis de los instrumentos que debe ser normalizado con los recientes criterios científicos y de acuerdo a los últimos desarrollos en el campo organológico. Unas cuantas observaciones son suficientes para cuestionarnos con respecto a la autenticidad de los parámetros de sonido manifiestos actualmente en estos órganos, comparado con las intenciones y deseos de los maestros organeros que los construyeron.

\section{A. LA AFINACIÓN DE LOS ÓRGANOS.}

Todo parece indicar que la afinación actual no es la original. Esto es evidente al analizar las chimeneas de las flautas semitapadas, las cuales son anormales en su longitud de acuerdo a lo usual en este tipo de construcción. Esta observación nos hace pensar que la afinación se alteró en su altura o que los tubos fueron cortados, de tal manera que tienen menor fuerza.

Desafortunadamente, las flautas de fachada antiguas ya no existen para darnos una muy valiosa información al respecto, particularmente a través de sus muescas de afinación.

\section{B. LA PRESIÓN DEL AIRE.}

Algunas pruebas de sonido que hemos realizado inyectando aire directamente a algunas flautas con la boca, nos permiten concluir que éstas pueden tener una mejor pronunciación y un mejor sonido, con una presión mayor a la actual. Ésta puede ser una primera explicación de la pérdida de fuerza en estos órganos.

Esta prueba realizada en varios registros nos da resultados muy alentadores. Al mismo tiempo, podemos deducir que si las flautas reaccionan positivamente aplicando una presión de viento mayor, la estabilidad de la afinación también se reforzará. Sin embargo, es probable que los órganos en su estado actual no se puedan tocar correctamente, si solamente incrementamos la presión del viento, pues algunos otros elementos podrían trabajar incorrectamente en el terreno de la mecánica, así como en el ámbito de la correcta alimentación y armonización de la tubería. 
En este sentido, nos causa sorpresa el pequeño tamaño de las compresoras que parecen ser muy pequeñas en comparación con el tamaño de los instrumentos. Estas compresoras en realidad, están concebidas para órganos de 10 a 20 registros, mientras que en este caso cada instrumento posee alrededor de 50 registros. Las compresoras podrían encerrarse en cajas insonorizadas, pues actualmente están a la intemperie.

\section{El MECANISMO.}

Los teclados fueron modificados durante el siglo XIX. Más bien parecen teclados para piano o fortepiano. Sus teclas largas, nos muestran la evolución que tuvieron las teclas a lo largo del siglo XIX. Si los teclados fueron cambiados con nuevas dimensiones en las teclas, es lógico pensar en una serie de consecuencias al interior del órgano:

Primero, la perpendicularidad del mecanismo.

Posteriormente y como consecuencia, una probable modificación de la apertura de las válvulas $y$, por lo tanto, de las condiciones de alimentación del viento en las flautas.

Finalmente, la inconsistencia de los movimientos mecánicos.

Todos estos parámetros están conectados intrínsecamente.

Ésta es la razón por la que, cuando hay modificaciones en las dimensiones de los teclados, aparentemente inofensivas, traen consigo algunas consecuencias graves en la concepción original de los órganos.

\section{El SECRETO.}

Los secretos de los dos órganos tienen problemas de compresión; éste es un elemento fundamental a considerar, pues de ello, depende la calidad del sonido y la estabilidad de la afinación. Este problema es perjudicial para la entonación de los tubos y no permite la optimización del sonido.

Por otro lado, la resistencia de los tiradores de registros es demasiado suave, esto se hace obvio al ser manipulados y tirar de ellos. Esto no debe de verse como una cualidad, sino por el contrario como un problema de falta de hermeticidad en el secreto.

\section{Conclusión}

Estos pocos elementos descritos a manera de ejemplos, muestran de alguna manera que el propósito principal en la restauración hecha en la década de 1970, fue poner en orden los dos órganos, de tal forma que estuvieran en condiciones de ser tocados correctamente después de haber sido dañados por el fuego.

Para retribuir una sonoridad más acorde con la catedral, lo cual podría ser más "auténtico", es necesario ir más allá, y considerar en la situación actual una restauración a fondo de cada órgano. Es esencial que estos instrumentos recuperen, considerando el deterioro que han sufrido en los últimos años, su lugar en el contexto patrimonial, como objetos de culto y cultura.

66

(c) Consejo Superior de Investigaciones Científicas Licencia Creative Commons 3.0 España (by-nc)
Anuario Musical, 60 (2005)

http://anuariomusical.revistas.csic.es 
Un proyecto de estas dimensiones no puede llevarse a cabo seriamente sin un estudio profundo de cada órgano, de tal manera que podamos encontrar todas aquellas indicaciones que permitan restaurar los diferentes parámetros a sus valores originales: la presión del aire, la afinación de los órganos, los parámetros de entonación (la altura de las bocas, la apertura de los pies, la longitud de los cuerpos, etc.).

Ese estudio preliminar también sería una fuente documental muy importante, inexistente hasta ahora con el detalle que el proyecto reclama; podría constituir una memoria de los trabajos a realizar; y permitiría elaborar con detalle la propuesta de restauración, pues hay que señalar que es imposible conocer con precisión el contenido exacto de los trabajos de restauración, sin hacer antes tal estudio, que se podría llevar a cabo durante el desmantelamiento de los instrumentos, previo a la restauración.

Actualmente estamos en espera de una nueva restauración de los órganos de la catedral de México. Es indudable que estos instrumentos representaron una de las épocas de mayor esplendor artístico y cultural en México durante el siglo XVIII, por lo cual, actualmente su estudio, conservación y revalorización suponen un enorme compromiso. Su inserción en las nuevas estéticas del mundo del arte, así como su plena función en el esplendor litúrgico, le confieren una importancia primordial a la tarea de conservar esta herencia patrimonial.

\section{Bibliografía}

Fernando Antonio de MADRID: Cartas instructivas sobre los órganos. Jaén, en la imprenta de Pedro de Doblas 1790.

Gabriel SALDívaR: Historia de la Música en México (Épocas Precortesiana y Colonial). México D.F., Editorial Cultura , 1934.

Macario Santiago KASTNER: Contribución al estudio de la música española y portuguesa. Lisboa, UNAM 1941.

Manuel Toussaint: La Catedral de México y el Sagrario Metropolitano. México D.F., 1948.

Dirk A. Flentrop: The Organs of Mexico Cathedral. Washington, Smithsonian Institution Press, 1986.

Gustavo Delgado y Ofelia G. Castellanos: Los Órganos Históricos de la Catedral de México. México D.F., “Academia Mexicana de Música Antigua para Órgano, Vol. I”, 1993.

—: Órganos Históricos de Puebla y Tlaxcala. México D.F., inédito, 1998.

-: Órganos Históricos de Oaxaca. Estudio y Catalogación. México D.F., Fomento Cultural BANAMEX-INAH, 2000. 


\section{APÉNDICE}

Lista de los registros más frecuentes en la nomenclatura hispánica y sus equivalentes en nomenclatura portuguesa e inglesa.

\section{ESPAÑOL}

-Flautado de 52, 26, 13
palmos

-Flautado (segundo)

-Octava, $8^{\text {a }}$, Octava real.

-Docena $12^{\mathrm{a}}$

-Quincena, $15^{\mathrm{a}}$

-Dieciseptena, $17^{\mathrm{a}}$

-Diecinovena, $19^{\mathrm{a}}$

-Veintidocena, $22^{\mathrm{a}}$

-Lleno, Compuestas,

Compuestas de lleno

-Zímbala, Címbala
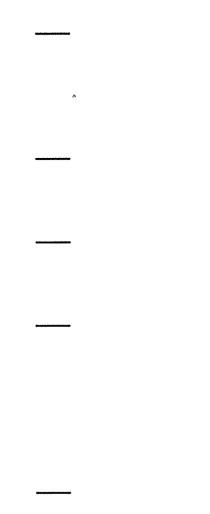

-Flautado de Violón,

\section{PORTUGUÉS}

Flautado

Flauto aberto, Aberto

de 24, 12 palmos

Doxe aberto, Diapazão

Voz Omana

Oitava, Prestão,

Flauto de 6 aberto

Dezenat Dozenat $12^{\mathrm{a}}$

Quintadecimat Quinzena

Decimasetimat $17^{\mathrm{a}}$

Decimanovena, $19^{\mathrm{a}}$

Ventidozenat $22^{\mathrm{a}}$

Cheio, Mistura

Simbala, Cheio, Resimbala

$12^{\mathrm{a}}+15^{\mathrm{a}}+19^{\mathrm{a}}$

$15^{\mathrm{a}}+19^{\mathrm{a}}$

$26^{a}+29^{a}$

Claras, Claram

Cheio $12^{\mathrm{a}}$ á 4 voces

Violão Bordas, Doze

\section{INGLÉS}

Diapasont 32ft., $16 \mathrm{ft}$. $8 \mathrm{ft}$.

Second diapason $8 \mathrm{ft}$.

Principal 4ft.

Twelfth 2 2/3 ft.

Fifteenth $2 \mathrm{ft}$.

Seventeenth $13 / 5 \mathrm{ft}$.

Nineteenth $11 / 3 \mathrm{ft}$.

Twenty-second $1 \mathrm{ft}$.

Mixture

Sharp mixture

Rauschpfeife $2 / 3 \mathrm{ft}$., $2 \mathrm{ft}$., $1 / 3 \mathrm{ft}$.

Rauschpfeife 2ft 11/3ft.

Cimbel 2/3ft. $+1 / 2 \mathrm{ft}$.

Sesquialtera or Tierce

Mixture

Mixture 2 2/3ft., 4 rks.

Bourdon 16ft, 


\begin{tabular}{|c|c|c|}
\hline Violón & $\begin{array}{l}\text { Flauto tapado } \\
\text { Flauto de } 12 \text { tapado }\end{array}$ & $\begin{array}{l}\text { Bourdon } 8 \mathrm{ft} \\
\text { Rohrflute } 8 \mathrm{ft} \text {. }\end{array}$ \\
\hline -Tapadillo, 8a tapada & Tapadillo, Tapadinho, & Flute $4 \mathrm{ft}$. \\
\hline - & Flauto de 6 tapado & \\
\hline -Nasardo en $12^{\mathrm{a}}$ & $12^{\mathrm{a}}$ & Nasard 2 2/3ft. \\
\hline -Nasardo en $15^{\mathrm{a}}$ & $15^{\mathrm{a}}$ & Flute $2 \mathrm{ft}$. \\
\hline -Nasardo en $17^{a}$ & $17^{\mathrm{a}}$ & Tierce $13 / 5 \mathrm{ft}$. \\
\hline -Pifano, Ocarina & - & Flute $4 \mathrm{ft}$ or $2 \mathrm{ft}$. \\
\hline -Nasardos de III hileras & Nasardos & Bass-Cornet 3 rks. \\
\hline -Corneta, Corneta real & Corneta & Cornet 5 or more rks. \\
\hline -Corneta Tolosana & - & Cornet 3 rks \\
\hline -Corneta de eco & Corneta en eco & Cornet in swell-box \\
\hline -Cara & - & Diapason $16 \mathrm{ft}, 8 \mathrm{ft}, 4 \mathrm{ft}$. \\
\hline -“Ple" catalán & - & Mixture \\
\hline -Simbalet & - & Sharp mixture \\
\hline -Flauta travesiera & Flauta travesa & Gemshorn $8 \mathrm{ft}, 1$ or 2 rks. \\
\hline & Flauta romana & Gemshorn $8 \mathrm{ft}$ \\
\hline
\end{tabular}

\section{REGISTROS DE LENGÜETA}

A continuación se presentan los más frecuentes registros de lengüeta y su nomenclatura en Español, Portugués e Inglés:

-Trompeta real (Trompeta interior vertical)
Trompeta real

Trumpet $8 \mathrm{ft}$.

\section{TromPETERÍA HORIZONTAL}

-Clarín de bajos

-Clarín
Clarim, Baixao

Clarim
Trumpet $8 \mathrm{ft}$. bass

Trumpet $8 \mathrm{ft}$. treble 
-Trompeta magna

-Bajoncillo

-Trompeta recortada

-Trompeta de Batalla

Clarín de Campaña

-Contras de Bombardas

-Gaita

-Chirimía

-Orlos, Dulzayna,

Regalía

-Viejos

-Viejas

-Tiorba

-Violeta

-Violeta de madera
Tromba major

Clarim, tromba

Trompa Castarda

Trompeta Batalha

Clarim Cabalha

Cheremia

Orlo, dulciana
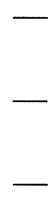

-
Trumpet $16 \mathrm{ft}$. treble

Clarion $4 \mathrm{ft}$. Bass

Trumpet $8 \mathrm{ft}$. with half $\mathrm{L}$.

Military or field trumpet

$8 \mathrm{ft}$., $4 \mathrm{ft}$.

Pedal bombarde $16 \mathrm{ft}$.

Schalmei 2ft. Bass

Schalmei 8ft.

Regal 8ft., bass and treble

Regal 8ft. Bass

Regal 8ft. Treble

Regal 16ft, or $8 \mathrm{ft}$. Treble

Rega12 ft. Bass

Rega1 2 ft. bass (wood)

\section{LENGÜETAS HORIZONTALES Y/O VERTICALES}

-Oboe

Oboe

-Fagote, oboe

Fagote

-Clarinete
Clarinete
Regal 8ft. or Schalmei $8 \mathrm{ft}$ or $16 \mathrm{ft}$.

Regal $8 \mathrm{ft}$.

Dulzian 8ft., oboe 8ft.

Krummhorn $8 \mathrm{ft}$. 